\title{
Alunos surdos e desafios do atendimento especializado para a aquisição de Língua Brasileira de Sinais (Libras) nas escolas municipais de Dourados, MS
}

\section{Deaf students and challenges of the special educational service for Brazilian sign language (Libras) acquisition at municipal schools in Dourados, MS}

Alumnos sordos y desafíos de la atención especializada para la adquisición del Lengua Brasileña de Señales (Libras) en las escuelas municipales de Dourados, MS

Aurélio da Silva Alencar ${ }^{1}$

Marilda Moraes Garcia Bruno ${ }^{1}$

IIma Regina Castro Saramago de Souza ${ }^{1}$

DOI: http://dx.doi.org/10.20435/serie-estudos.v23i48.1069

Resumo: A aquisição de linguagem e da Língua Brasileira de Sinais (Libras) pelo aluno surdo nos anos iniciais do Ensino Fundamental ainda é pouco estudada no meio acadêmico. Este artigo tem como objetivo discutir os desafios de atendimento especializado para a aquisição de linguagem/Libras de alunos surdos matriculados nas escolas municipais de Dourados, MS. O estudo fundamenta-se na perspectiva dos Estudos Surdos e na teoria Ecológica do Desenvolvimento Humano de Bronfenbrenner. Teve como metodologia a análise documental, a observação em sala de aula, as entrevistas com o professor surdo e com os intérpretes educacionais. Os resultados indicaram que: os alunos surdos chegam à escola sem o domínio de uma língua de comunicação; há baixa frequência ao Atendimento Educacional Especializado ( $A E E)$. Conclui-se que os intérpretes educacionais, além da função de interpretar as aulas, acabam por ensinar os alunos surdos, uma vez que os alunos pesquisados não frequentam as Salas de Recursos Multifuncionais (SRMs) e aprendem Libras por meio do intérprete educacional (IE) em sala de aula.

\footnotetext{
${ }^{1}$ Universidade Federal da Grande Dourados (UFGD), Dourados, Mato Grosso do Sul, Brasil.
} 
Palavras-chave: aquisição de Língua Brasileira de Sinais (Libras); surdez; atendimento especializado.

Abstract: The acquisition of language and Libras by the deaf student in the initial years of Elementary School is still little studied in the academic world. This article aims to discuss the challenges of special educational service for the Sign Language acquisition for deaf students enrolled at municipal schools in the city of Dourados, MS, Brazil. The study is based upon the perspective of Deaf Studies and Bronfenbrenner's Ecological Theory of Development Human. The methodologies used were: document analysis, classroom observation, interviews with deaf teachers and sign language interpreters. Results showed that deaf students come to school with no command for any communication. Low attendance to Special Educational Service (AEE). It can be concluded sign language interpreters have a double function, because they not only interpret the classes but also teach deaf students, since students do not attend the Multifunction Resources Rooms (SRMs) and learn Sign Language by having the sign interpreters in the classroom.

Keywords: Brazilian sign language acquisition (Libras); deafness; special educational service.

Resumen: La adquisición del lenguaje y de Libras por el alumno sordo en los años iniciales de la Enseñanza Fundamental todavía es poco estudiada en el medio académico. Este artículo tiene como objetivo discutir los desafíos de la atención especializada para la adquisición del lenguaje/Libras de alumnos sordos matriculados en las escuelas municipales de Dourados, MS, Brasil. El estudio se fundamenta en la perspectiva de los Estudios Sordos en la teoría Ecológica del Desarrollo Humano de Bronfenbrenner. Tuvo como metodología el análisis documental, la observación en aula, las entrevistas con el profesor sordo y con los intérpretes educacionales. Los resultados indicaron que: los alumnos sordos están en la escuela sin el dominio de una lengua de comunicación; hay baja frecuencia a la Atención Educacional Especializada (AEE). Se conclui que los intérpretes educacionales allá de su función de interpretar las clases, también enseñan los alumnos sordos, una vez que los alumnos investigados no frecuentan las Salas de Recursos Multifuncionales-SRM, aprendiendo Libras por el medio del intérprete educacional (IE) en aula, en el momento de la traducción e interpretación.

Palabras clave: adquisición de Lengua Brasileña de Señales (Libras); sordera; atención especializada.

\section{INTRODUÇÃO}

O processo de aquisição de linguagem/Língua de Sinais por alunos surdos nos anos iniciais do Ensino Fundamental é uma temática complexa, desafiadora e pouco estudada e que merece maior debate no meio científico. Estudos linguísticos apontam para a importância da oferta de melhores oportunidades de interação, comunicação e domínio da Língua de Sinais como forma de mediação para o acesso ao conhecimento e para a promoção da aprendizagem de alunos surdos.

Numa perspectiva bilíngue, considerando a Língua de Sinais como a primeira língua para o surdo, a L1, e a Língua Portuguesa como a segunda, a L2, e entendendo que são línguas distintas de comunicação, torna-se essencial compreender 
como se dá o processo de aquisição da linguagem/Língua de Sinais nos anos iniciais do Ensino Fundamental. Isto implica estudar a atuação do professor de Libras e a atuação do intérprete de Libras, denominado, neste estudo, como intérprete educacional (IE), como formas de mediação ao processo de aquisição da Língua de Sinais e de otimização da aprendizagem do aluno surdo.

Além da importância do ensino de Libras no Atendimento Educacional Especializado (AEE), desde a mais tenra idade, pelo professor surdo, o intérprete educacional tem papel fundamental no processo ensino aprendizagem do aluno surdo, pois é pela tradução e interpretação que o conteúdo transmitido verbalmente pelo professor regente é mentalmente reestruturado para a Língua de Sinais, por meio de uma estrutura adequada ao entendimento do aluno surdo. Desse modo, ele poderá interagir e aprender como os demais alunos ouvintes.

O Decreto n. 5.626/2005 prevê a presença dos intérpretes de Libras somente para a segunda etapa do Ensino Fundamental e para os níveis posteriores. Para os anos iniciais, é prevista a presença de professor regente bilíngue em salas de aula, cuja língua de instrução seja a Libras. Apesar disso, esta não é uma realidade do município estudado, os intérpretes são disponibilizados aos alunos surdos da Rede Municipal de Ensino, em todos os anos em que estejam matriculados. Não existe uma sala de aula em que a língua de instrução seja a Libras; por conta disso, a investigação neste trabalho se dá nos anos iniciais do Ensino Fundamental, nos quais estão inseridos os alunos surdos e os intérpretes educacionais.

$\mathrm{Na}$ concepção de desenvolvimento humano de Bronfenbrenner, "[...] o ambiente ecológico é tido como uma série de estruturas encaixadas, uma dentro da outra, como um conjunto de bonecas russas. No nível mais interno, está o ambiente mais imediato contendo a pessoa em desenvolvimento. Este pode ser a casa, a sala de aula [...]" (BRONFENBRENNER, 1996, p. 5). Portanto o indivíduo não é considerado isoladamente, e seu desenvolvimento acontece levando-se em conta os vários sistemas nos quais ele está inserido.

Com as crianças surdas, a situação não é diferente, elas nascem e crescem em ambientes familiares, são rodeadas por pessoas, convivem com vizinhos, filhos de amigos dos pais, frequentam igrejas e praças; contudo é a partir da escolarização que elas ampliam seus ambientes e o círculo de interação: passam a conviver com outras pessoas, professores, colegas de turma e de escola, tendo 
nessa vivência a comunicação como ponto mais divergente de interação com os demais. O que as diferencia é a forma de comunicação, enquanto o aluno surdo se utiliza da Língua Brasileira de Sinais (Libras), linguagem visual espacial, os demais participantes de seu microssistema utilizam a linguagem oral auditiva, ou seja, a Língua Portuguesa falada.

A aquisição da linguagem pela criança surda passa por processos semeIhantes aos das crianças ouvintes, contudo a família pode levar muito tempo até perceber a surdez, o que acarreta perdas significativas no processo de desenvolvimento linguístico dessa população. O contato com a Língua de Sinais tem sido tardio para as crianças surdas brasileiras, estas têm, muitas vezes, o primeiro contato com a Libras apenas no momento em que ingressam na escola.

Estudos realizados sobre a temática da Educação Especial com foco na surdez e na atuação do intérprete educacional no Brasil apontam que o número de alunos surdos matriculados vem se ampliando a cada ano (QUILES, 2015a).

Nos últimos anos, a matrícula de alunos surdos tem aumentado também na Rede Municipal de Dourados (Censo Escolar SEMED 2011/2015) e o que se observa é que as crianças estão chegando às escolas sem conhecimento de Libras.

Essas questões têm nos instigado a questionar: Por que as crianças surdas não tiveram acesso à Libras? Como tem atuado o professor bilíngue surdo no espaço do AEE? Qual o papel do intérprete educacional no processo de aquisição de Língua de Sinais? Somente a interpretação em sala de aula garante o domínio linguístico pelo aluno surdo?

Tendo em vista as questões apresentadas, o objetivo da pesquisa foi o de discutir os desafios do atendimento especializado para a aquisição de linguagem/ Libras de alunos surdos matriculados nas escolas municipais de Dourados, MS. O trabalho está dividido em duas sessões, a sessão primeira discute o microssistema escola, a partir da teoria de Bronfenbrenner (1996) e o campo selecionado para a pesquisa. A segunda sessão analisa a Educação Especial no Estado do Mato Grosso do Sul e o atendimento especializado para o aluno surdo no município de Dourados, MS.

Espera-se que as discussões aqui realizadas permitam reflexões e ações para o redimensionamento dos serviços ofertados e a melhoria no atendimento especializado para o processo de aquisição de linguagem/Libras, assim como o desenvolvimento do processo de aprendizagem dos alunos surdos no contexto escolar. 


\section{MICROSSISTEMA “ESCOLA” E O CAMPO DA PESQUISA}

Para a investigação do processo de desenvolvimento linguístico e da aprendizagem da criança surda, mediados pela comunicação com o professor surdo e pelo intérprete educacional, esta pesquisa parte da compreensão de que a criança surda participa de um sistema que Bronfenbrenner (1996) conceitua como crescimento bioecológico do desenvolvimento humano. São eles: o microssistema, o mesossistema, o exossistema e o macrossistema, conforme se explica a seguir:

- Microssistema - um complexo de inter-relações dentro de um ambiente imediato, onde ocorre a interação face a face, sendo constituído pelos locais onde a criança vive, neste caso a família, os colegas, o professor surdo, o intérprete e o professor regente, são as pessoas com as quais interage e pelas atividades que se desenvolvem em conjunto.

- Mesossistema - um conjunto de inter-relações entre dois ou mais ambientes em que a pessoa em desenvolvimento participa ativamente, são as relações entre os vários microssistemas, neste trabalho as relações entre a família, escola, $A E E$, os professores e outros profissionais envolvidos direta ou indiretamente no processo de aprendizagem.

- O exossistema - ambientes que não envolvem a pessoa em desenvolvimento como participante ativo, mas que a afetam.

- O macrossistema - o complexo de sistemas encaixados, interconectados, considerados como manifestação de padrões globais de ideologia, as políticas públicas e a organização das instituições sociais a uma determinada cultura ou subcultura, que irão influenciar o indivíduo em desenvolvimento (BRONFENBRENNER, 1996).

Ao nascer, a criança começa a fazer parte do ambiente familiar e receberá todos os cuidados que poderão facilitar ou dificultar o seu desenvolvimento. Esse local passa a ser para ela seu primeiro microssistema, onde terá relações face a face com os pais e com os demais membros da família. Ao perceber a surdez, os pais passam a frequentar outros espaços como, por exemplo, clínicas especializadas em deficiência auditiva, médicos, fonoaudiólogos. Nesse momento, a criança terá contato e fará interações com outras pessoas, além dos pais, e em outros ambientes, além do familiar. O conjunto de todos os ambientes (dos quais a criança surda participa ativamente) é definido como mesossistema. 
Nesta pesquisa, deu-se ênfase ao microssistema "escola", que envolve espaços de interação e aprendizagem como a sala de aula, o AEE e os outros espaços de cultura e recreação. No microssistema "escola", foram analisadas as díades: aluno surdo-professor surdo; aluno surdo-intérprete educacional; aluno surdo-professor regente; aluno surdo-alunos ouvintes.

Para a análise dos dados, Bronfenbrenner (1996) orienta que uma pesquisa ecológica deve conter o maior número de dados relativos aos sistemas participados pela pessoa em desenvolvimento. A partir das orientações do autor, a pesquisa de campo consistiu na investigação acerca da atuação do professor surdo do AEE e do intérprete educacional, em anos iniciais do Ensino Fundamental, na interação com três alunos surdos em escolas da Rede Municipal de Ensino.

Os participantes da pesquisa foram: uma professora surda da SRM e três intérpretes educacionais. O critério de seleção dos alunos pautou-se por suas matrículas nos anos iniciais do Ensino Fundamental e na SRM. Foram feitas observações em três salas de aula das escolas selecionadas, o que totalizou 26 horas de observação, cujo objetivo foi verificar as interações entre o aluno surdo e o intérprete educacional, entre o aluno surdo e a professora regente e entre o aluno surdo e os alunos ouvintes.

No processo de análise, os dados selecionados foram organizados em três eixos temáticos a partir das formas de interações nos diferentes contextos: sala de aula, espaço da sala de recursos e formas de comunicação no contexto familiar. Os eixos temáticos permitiram a análise e a discussão em torno da atuação do professor bilíngue, relativa a estratégias, avanços, dificuldades e desafios; da atuação do intérprete educacional no contexto escolar, relacionada a estratégias, avanços e desafios; no entanto, conforme mencionado anteriormente, a abordagem deste trabalho será a escola e nos desafios do atendimento para a aquisição de linguagem/Libras para alunos surdos.

\section{A EDUCAÇÃO ESPECIAL E O ATENDIMENTO ESPECIALIZADO PARA O ALUNO SURDO EM DOURADOS - MATO GROSSO DO SUL}

A aquisição de Língua de Sinais por crianças surdas tem se constituído, em vários países e no Brasil, direito linguístico inserido no campo dos direitos humanos fundamentais tal como os demais direitos sociais, políticos, econômicos e culturais. Assim, a questão linguística e a aquisição de uma língua assumem centralidade na educação dos surdos. 
O estado de Mato Grosso do Sul tem apresentado uma política de atendimento ao aluno surdo, contemplando as escolas com os serviços de apoio educacional, com intérpretes de Libras, com instrutores surdos e Salas de Recursos Multifuncionais. Assegura também, na contratação dos profissionais que atuarão com os alunos surdos, a preferência por professor surdo para o AEE nas SRMs. Na cidade de Dourados, MS, todos os alunos surdos matriculados na rede pública de ensino têm assegurado o apoio do intérprete educacional em sala de aula e o AEE, na SRM, no contraturno ao da escolarização.

Em sua tese de Doutorado, Quiles (2015b) faz vasta explanação relativa à legislação da Educação Especial no Mato Grosso do Sul, pontuando que o estado de MS foi criado em primeiro de janeiro de 1979 e que os serviços vinculados ao campo da Educação Especial datam de 1981. A autora sinaliza que o Núcleo de Educação Especial fica responsável pela avaliação dos alunos encaminhados pela escola; pela organização dos serviços; pela orientação às famílias e pelo acompanhamento da prática pedagógica, tanto dos professores regentes, quanto dos profissionais que atuam no atendimento educacional especializado. São eles: tradutores e intérpretes de Libras, guia-intérprete, professores de apoio em classe comum, itinerante domiciliar, instrutor mediador, e professor de Sala de Recurso Multifuncional.

Especificamente sobre o instrutor mediador, Quiles (2015b) relata que esse profissional é uma particularidade do estado do Mato Grosso do Sul. Ele não é citado no Decreto 5.626/2005, e sua atuação se dá quando o aluno surdo não domina a Língua de Sinais. Assim diz a autora:

Segundo o material organizado pelo CAS, o instrutor mediador surgiu em 2003 no estado para apoiar alunos surdocegos que ainda se encontravam em fase de aquisição da língua. Porém, considerando que muitos alunos surdos chegam à escola sem terem acesso à Língua de Sinais optou-se pela contratação deste profissional - instrutor mediador- para apoiá-los na aquisição de sua língua viso-gestual, pois considerou-se que a atuação do intérprete de Libras/Língua Portuguesa só seria viável e adequada após o domínio da Libras pelo aluno surdo. (QUILES, 2015b, p. 71).

Os intérpretes mediadores atuam na acessibilidade do conteúdo acadêmico ao aluno surdo a partir dos conteúdos das aulas. Ainda conforme a autora, o Centro de Capacitação de Profissionais da Educação e de Atendimento às Pessoas com Surdez (CAS) orienta que o instrutor mediador deve tornar as aulas acessíveis ao 
aluno surdo a partir do planejamento do professor, ou seja, esses profissionais devem atuar mediante a aula pensada pelo professor regente e, de posse de seu planejamento, este saberá que estratégias ou adaptações fará para que o aluno surdo entenda o conteúdo ministrado pelo professor. Como ainda se encontram na fase de aquisição de linguagem, os alunos surdos têm seu aprendizado mediado pelo instrutor mediador e só terão o acompanhamento do intérprete quando forem fluentes em Libras.

A situação do instrutor mediador, referida na tese de Quiles, ocorre de forma muito semelhante nas escolas da Rede Municipal de Ensino de Dourados. Devem-se considerar dois fatores determinantes: o primeiro, o pequeno número de professores surdos para atuação no AEE em Dourados, e o segundo, o fato de os profissionais intérpretes terem sido capacitados pelo CAS, órgão que tem ajudado a pensar o atendimento ao surdo no Estado. O termo "intérprete mediador" foi entendido como uma variação do termo "instrutor mediador", presente no Plano Estadual de Educação e nas orientações do CAS-MS, relatados na tese de Quiles (2015b).

Os IEs de Dourados têm assumido a postura de "mediadores do conhecimento" por entenderem que sua função realmente difere da função do intérprete de Libras que atua na área da educação. Como o observado nas salas de aula, os IEs atuam praticamente como professores dos alunos surdos, participando da construção do conhecimento por meio de atividades diferenciadas, trazidas pelo professor regente ou pelos próprios IEs. Eles usam esses mesmos materiais para o ensino dos termos desconhecidos pelos alunos surdos, o que caracteriza o ensino de Libras em sala de aula, apesar de nenhum intérprete mediador assumir essa função, já que é sabido que deve ser feita pelo professor ou instrutor surdo em contraturno da escolarização, e não na sala de aula.

Cabe mencionar que, no município de Dourados, MS, como nas demais cidades do interior do Estado, as crianças surdas chegam à escola sem a aquisição de uma língua e sem o domínio da Língua Brasileira de Sinais, e, quando elas são matriculadas nas escolas municipais, a Secretaria Municipal de Educação (SEMED) disponibiliza um intérprete educacional, que, nesse caso, faz o papel de instrutor mediador. Esses intérpretes são professores com licenciatura em alguma graduação e fluentes em Libras, avaliados pelo Exame de Proficiência em Libras (PROLIBRAS), realizado pelo MEC, ou a avaliação de proficiência em Libras pelo 
CAS. Para esses alunos surdos também é oferecido o AEE na SRM. Entende-se que o Estado reconhece a necessidade do ensino de Libras, mas isso não se efetiva em políticas públicas de estímulo à participação dos alunos surdos nas Salas de Recursos Multifuncionais, como forma de fortalecimento da aquisição de Libras por alunos surdos, principalmente pelo fato de ser uma professora surda a profissional responsável pelo atendimento em Libras dos alunos surdos.

Conforme a organização dos atendimentos, a professora surda deveria estar o dia todo na mesma escola polo para atender os alunos no contraturno, como prevê o Decreto 5626/2005. Contudo, pela estratégia adotada, a professora deslocava-se em dias alternados para as duas escolas, o que fazia com que ela atendesse os alunos surdos em apenas duas horas por atendimento, divididos em: AEE para o ensino de Libras (uma hora) e AEE para o ensino de Língua Portuguesa (uma hora). A professora relatou que essas duas horas deveriam ser direcionadas exclusivamente ao ensino de Libras. O ensino de Língua Portuguesa, como L2, deveria ser realizado por um professor ouvinte, conforme pondera:

Por exemplo, eu sonho eu ensinar L1 e o professor de português ouvinte ensina L2. Para caminhar junto. Consegue. Eu sozinha ensinar L1 e L2 é difícil. Português é difícil. (Professora Surda).

O relato da professora ilustra o limite do componente pedagógico tanto para o ensino de Libras quanto para o de Língua Portuguesa, pontua ainda a sua dificuldade para ensinar a Língua Portuguesa escrita.

Os dados indicam que a professora surda tenta focar seu trabalho no ensino de Libras, solicitando apoio de um professor de Língua Portuguesa para o ensino de L2 que, na opinião dela, também deveria ser professor bilíngue. Considera que, para ela, como surda e usuária de Libras como língua materna, não há impedimento para ensinar essa língua às crianças surdas, o que se configura o ideal: "uma díade em atividade conjunta" (BRONFENBRENNER, 1996). A criança surda precisa ser exposta à Língua de Sinais para que a aquisição da linguagem seja efetiva. A falta da composição de uma díade entre a criança surda e seu par usuário da Língua de Sinais pode prejudicar seu desenvolvimento, tanto linguístico quanto acadêmico.

No entanto observa-se que apenas a oferta do serviço não determina o acesso, pois as condições ambientais, socioculturais e econômicas dos alunos e de suas famílias não Ihes favorecem o acesso aos serviços. Essa é uma tarefa a ser pensada coletivamente entre o macrossistema (política e gestão de educação 
especial), o mesossistema (aqui entendido como a comunidade surda e suas redes de apoio) e o microssistema (a família, a escola, os professores que atuam com os alunos surdos, os intérpretes educacionais, diretamente envolvidos com a aprendizagem do aluno surdo).

O papel do intérprete no contexto da educação infantil e no Ensino Fundamental foi discutido por Lacerda $(2009,2015)$. A autora explica que o tradutor e intérprete de Libras/Língua Portuguesa que atua em espaços escolares, possui uma função diferenciada em relação ao profissional que atua em outros espaços sociais.

Numa proposta de educação bilíngue (LACERDA; GOES, 2000; QUADROS; KARNOPP, 2004), o desenvolvimento linguístico e a aprendizagem de Libras pelos alunos surdos dependem da atuação específica do professor de Libras, que atuará no ensino de Libras todos os dias no contraturno, do professor de Língua Portuguesa, também bilíngue, que atua no AEE e do intérprete educacional, que atua no espaço da sala de aula. Nesse sentido, Lacerda e Goes (2000) é enfática ao ponderar que, ao sinalizar, a criança desenvolve sua capacidade e sua competência linguística numa língua que Ihe servirá depois para aprender uma segunda língua, a do grupo majoritário. Dessa forma, a aquisição de Libras se caracteriza como uma forma de comunicação e de aquisição de linguagem que dependem da contínua exposição a essa língua para a aquisição de formas mais elevadas de comunicação e linguagem.

O que se evidencia neste estudo é que o intérprete, além de se organizar para realizar a sua função, deve se preocupar em ensinar Libras ao aluno surdo, uma vez que grande parte das escolas que atendem o aluno surdo, não conta com AEE na Sala de Recursos Multifuncionais; mesmo nas que contam com a sala na escola polo, percebeu-se que os alunos surdos pesquisados não frequentam esse atendimento, quer pela dificuldade em os pais ou responsáveis estarem levando essas crianças ao atendimento, quer pela distância que as escolas polo têm em relação à escola que o aluno surdo estuda. Por conta disso, os intérpretes têm se esforçado para darem conta de uma tarefa que não lhes cabe: o ensino de Libras e dos conteúdos do aluno surdo.

Nas salas de aula, verificou-se que os professores regentes pouco interagiam com os alunos surdos, as díades observadas entre professor regente e aluno surdo resumiam-se basicamente a acenos de positivo e negativo por parte dos professor, 
geralmente quando o aluno surdo o procurava para mostrar alguma atividade, sob a orientação do intérprete; que a participação desses alunos na aula se dá quase que unicamente pela interação com o intérprete educacional, seja nas atividades pedagógicas, seja na mediação com o professor regente. Nesse sentido, o aluno surdo está presente na sala de aula da escola regular, mas não faz parte dela.

A pouca participação dos alunos no AEE sobrecarrega o intérprete educacional com mais uma função: a de ensinar Libras no momento da atuação em sala de aula, quando os alunos surdos deveriam aprender Libras no contato com o professor surdo na Sala de Recursos Multifuncionais. Com isso, o IE faz muito além da função de interpretar as aulas, acaba ensinando Libras na sala de aula. Para modificar essa situação, deve-se estimular a participação dos alunos no AEE onde, por meio da interação com o professor surdo, terá a aprendizagem de Libras no espaço da escola, mais adequado à aquisição, a SRM.

Muitos alunos surdos não participam do AEE na SRM, logo, a única opção de interação em Libras para esses alunos é a díade aluno surdo e intérprete educacional. Outro fator agravante dessa situação é que, nas escolas pesquisadas, havia apenas um aluno surdo na escola, inviabilizando o contato entre os pares surdos. E é no momento da tradução e interpretação em Libras que acontece o ensino de Libras, ao mesmo tempo em que há a tradução e a interpretação dos conteúdos curriculares ministrados pelo professor regente. Observaram-se poucas interações entre os alunos surdos e os alunos ouvintes, essas interações limitavam-se, na maioria dos casos, à solicitação de materiais emprestados (lápis de cor, apontador e borracha) e a brincadeiras nos intervalos do recreio com alguns colegas mais próximos.

\section{CONSIDERAÇÕES FINAIS}

Os resultados da pesquisa mostraram que, assim como em outros municípios de Mato Grosso do Sul, Dourados avançou na oferta do atendimento aos alunos surdos, porém os alunos continuam chegando às escolas sem uma língua de instrução e aprendem a Libras por meio da atuação do intérprete educacional, que, muitas vezes, faz a função de professor de Libras desse aluno. A organização do atendimento ao aluno surdo nas Salas de Recursos Multifuncionais deve ser repensada. Como demonstraram os dados da pesquisa, os momentos de AEE não estão sendo efetivos. É preciso que haja investimentos tanto nas estruturas 
das salas implantadas, quanto na formação de mais profissionais surdos para atuarem nesses espaços, bem como ações de prevenção junto aos pais para que não ocorram mais situações de desistência nos atendimentos, sob a justificativa de dificuldades de deslocamento ao atendimento. Entende-se que essa situação seria contornada se houvesse período integral em que os professores surdos e os ouvintes fluentes em Libras, com estratégias linguísticas e metodológicas de ensino de L1 e L2, pudessem atuar com os alunos surdos na própria escola.

A metodologia utilizada, as observações, as entrevistas e a análise dos dados permitiram chegar aos resultados da pesquisa, os quais apontam que os alunos surdos de Dourados chegam à escola sem conhecimento em Libras; que a presença e a participação de profissionais surdos na educação bilíngue ainda se apresentam de forma reduzida e incipiente nas escolas municipais de Dourados, MS, pois há somente uma professora surda para atender a demanda do ensino de Libras aos educandos surdos matriculados em diferentes escolas e bairros da cidade. Por conta disso, a Secretaria Municipal de Educação, por meio do Núcleo de Educação Especial (NUEDESP), optou por oferecer o atendimento aos alunos surdos em dois pontos da periferia da cidade, de modo que a professora surda pudesse atender os alunos surdos de cada região.

Os resultados da pesquisa convergem com os apontamentos do estudo de Quiles (2015b) sobre a Educação de Surdos no estado de Mato Grosso do Sul, que não se mostrou plenamente inclusiva, apresentando vários problemas nessa direção, assim como não se mostrou plenamente bilíngue, já que a Língua de Sinais não ocupa lugar central nas atividades escolares. A situação do intérprete mediador também precisa ser mais bem estudada, ele não é um professor do aluno surdo, já que sua função se difere da função do docente, tampouco é um intérprete de Libras, uma vez que os alunos atendidos por esse profissional não dominam a Língua de Sinais.

Assim, este estudo contribuiu para a compreensão dos avanços, dos limites, mas especialmente dos desafios para a aquisição de linguagem/Libras para alunos surdos, bem como para novas discussões da educação bilíngue inclusiva no município de Dourados, MS. 
Alunos surdos e desafios do atendimento especializado para a aquisição de linguagem/Libras nas escolas municipais de Dourados, MS

\section{REFERÊNCIAS}

BRASIL. Decreto n. 5.626, de 22 de dezembro de 2005. Regulamenta a Lei n. 10.436, de 24 de abril de 2002, que dispõe sobre a Língua Brasileira de Sinais- Libras, e o art. 18 da Lei n. 10.098, de 19 de dezembro de 2000. Disponível em: <http://www.planalto.gov.br/ ccivil_03/_ato2004-2006/2005/decreto/d5626.htm>. Acesso em: 29 maio 2016.

BRONFENBRENNER, Urie. A ecologia do desenvolvimento humano: experimentos naturais e planejados. Tradução de Maria Adriana Verissimo Veronese. Porto Alegre: Artes Médicas, 1996.

LACERDA, Cristina Broglia Feitosa de; GOES, Maria Cecília Rafael de. O intérprete de Língua de Sinais no contexto de uma sala de aula de alunos ouvintes: problematizando a questão. In: LACERDA, Cristina Broglia Feitosa de; GÓES, Maria Cecília Rafael de (Org.). Surdez: processos educativos e subjetividade. São Paulo: Lovise, 2000b. p. 51-84.

LACERDA, Cristina Broglia Feitosa de. Intérprete de Libras em atuação na educação infantil e no ensino fundamental. Porto Alegre: Mediação/FAPESP, 2015.

. Intérprete de Libras em atuação na educação infantil e no ensino fundamental. Porto Alegre: Mediação/FAPESP, 2009.

QUADROS, Ronice Muller; KARNOPP, Lodenir Becker. Língua de Sinais Brasileira: estudos linguísticos. Porto Alegre: Artmed, 2004a.

QUILES, Raquel Elizabeth Saes. Educação de surdos e deficientes auditivos: uma análise dos indicadores sociais. Revista Educação Especial, Santa Maria, RS, v. 28, n. 51, p. 53-66, jan./abr. 2015a. Disponível em: <http://periodicos.ufsm.br/educacaoespecial/article/ view/4834/pdf>. Acesso em: 1ㅇa. ago. 2016.

. Educação de surdos em Mato Grosso do Sul: desafios da educação bilíngue e inclusiva. 2015. Tese (Doutorado em Educação Especial) - Universidade Federal de São Carlos, São Carlos, SP, 2015b. Disponível em: <https://repositorio.ufscar.br/handle/ ufscar/8061?show=full>. Acesso em: 8 ago. 2016.

\section{Sobre os autores:}

Aurélio da Silva Alencar: Mestre em Educação pela Universidade Federal da Grande Dourados (UFGD). Especialista em Educação Especial, Educação Especial com enfoque na Surdez e em Docência de Libras. Bacharel em Letras-Libras, Intérprete de Libras- Língua Brasileira de Sinais. E-mail: aureliotutor@hotmail.com

Marilda Moraes Garcia Bruno: Doutora em Educação pela Universidade Estadual Paulista "Júlio de Mesquita Filho". Professora associada da Universidade Federal da Grande Dourados (UFGD), docente do Programa de Pós-graduação em Educação 
da Faculdade de Educação. Líder do Grupo de Estudos e Pesquisas em Educação Inclusiva (GEPEI). E-mail: mgbruno@ufgd.edu.br

Ilma Regina Castro Saramago de Souza: Mestre em Educação e Doutoranda em Educação pela Universidade Federal da Grande Dourados (UFGD). Membro do Grupo de Pesquisa em Educação Inclusiva (GEPEI).E-mail: ilmasaramago@hotmail.com

Recebido em maio de 2017

Aprovado em fevereiro de 2018 